\title{
Penyuluhan Tentang Penanganan Udem Pada Kaki Dan Kecemasan Pada Ibu Hamil Trimester III Di Puskesmas Air Dingin Padang
}

\author{
Rini Rahmayanti ${ }^{1}$, Delvi Hamdayani ${ }^{2}$, Yaumul Rhama Saputra ${ }^{3}$, \\ Ria Utami Yuliani ${ }^{4}$, Darmaji Efrad ${ }^{5}$ \\ 1,2,3,4,5Program Studi S1 Keperawatan STIKes MERCUBAKTIJAYA Padang \\ Corresponding Email : rinie.rahmayanti@gmail.com
}

\begin{abstract}
ABSTRAK
Resiko kehamilan cukup membuat resah ibu hamil, meskipun diketahui dalam proses kehamilan akan terjadi perubahan-perubahan fisik maupun psikologis. Perubahan fisik tersebut berupa peningkatan hormon yang juga dapat mempengaruhi suasana hati seseorang, sakit punggung, kram atau kesemutan kaki, dan kaki bengkak yang sering terjadi di malam hari dan mengganggu kualitas tidur ibu hamil. Tujuan kegiatan ini adalah memberikan pengetahuan kepada ibu hamil tetang udem dan kecemasan pada trimester III dan terapi komplementer yang dapat dilakukan, Kegiatan ini dilakukan dengan metode ceramah, diskusi dan demonstrasi. Kegiatan ini dilaksanakan pada tanggal 10 oktober 2019 dan diikuti oleh 22 orang ibu hamil. Didapatkan hasil adanya peningkatan pengetahuan, pemahaman, dan kemampuan peserta dalam memahami materi yang disampaikan pada kegiatan pengabdian ini. Didapatkan $80 \%$ Audiens yang hadir mampu menyebutkan pengertian udem kaki dan kecemasan, 75\% Audiens yang hadir mampu menyebutkan dan mendemonstrasikan cara rendam kaki air hangat. Pendidikan kesehatan ini dapat dilakukan oleh tenaga kesehatan untuk meningkatkan pengetahuan ibu hamil tentang udem dan kecemasan serta penanganannya.
\end{abstract}

Kata Kunci : Udem, Kecemasan, Ibu Hamil, Trimester III

\section{ABSTRACT}

The risk of pregnancy is quite anxious for pregnant women, although it is known that physical and psychological changes will occur in the pregnancy process. These physical changes are in the form of increased hormones which can also affect a person's mood, back pain, leg cramps or tingling, and swollen feet that often occur at night and interfere with the quality of sleep of pregnant women. The purpose of this activity is to provide knowledge to pregnant women about edema and anxiety in the 3rd trimester and complementary therapies that can be done. This activity is carried out by the method of lectures, discussions and demonstrations. This activity was held on October 10, 2019 and was attended by 22 pregnant women. The results obtained were an increase in the knowledge, understanding, and ability of participants in understanding the material presented in this service activity. It was found that $80 \%$ of the audience present were able to mention the meaning of foot edema and anxiety, $75 \%$ of the audience present were able to mention and demonstrate how to soak feet in warm water. Health education can be carried out by health workers to increase the knowledge of pregnant women about edema and anxiety and its handling.

Keywords : Udem, Anxiety, Pregnant Women, 3rd Trimester

\section{PENDAHULUAN}

Angka kematian ibu di dunia saat melahirkan ataupun setelah melahirkan masih cukup tinggi, terutama di negara-negara berkembang. Tercatat pada tahun 2010 sebesar 24 per 100 ribu kelahiran, 
pada tahun 2011 sebesar 27 per 100 ribu kelahiran 2012 sebesar 23 per 100 ribu kelahiran sedangkan pada tahun 2016, selama 2 bulan tercatat 2 per 100 ribu kelahiran hidup telah meninggal dunia. Penyebab kematian ibu disebabkan oleh beberapa hal, yaitu preeklamsi, eklamsi, perdarahan, dan penyakit penyerta (Depkes, 2016).

Resiko kehamilan cukup membuat resah ibu hamil, meskipun diketahui dalam proses kehamilan akan terjadi perubahan-perubahan fisik maupun psikologis. Perubahan fisik tersebut berupa peningkatan hormon yang juga dapat mempengaruhi suasana hati seseorang, sakit punggung, kram atau kesemutan kaki, dan kaki bengkak yang sering terjadi di malam hari dan mengganggu kualitas tidur ibu hamil. Edema kaki atau pembengkakan pada kaki ditemukan sekitar $80 \%$ pada ibu hamil trimester III, terjadi akibat dari penekanan uterus yang menghambat aliran balik vena dan tarikan gravitasi menyebabkan retensi cairan semakin besar (Coban \& Sirin, 2010). Edema kaki fisiologis menyebabkan ketidaknyamanan, perasaan berat, dan kram di malam hari (Coban \& Sirin, 2010) dalam (Nurhasanah, 2013). Edema bisa menunjukkan adanya tanda-tanda bahaya dalam kehamilan apabila edema dimuka atau di jari, sakit kepala hebat, penglihatan kabur sebagai akibat dari pre eklampsia (Purwaningsih, 2012 dalam (Nurhasanah, 2013)).

Menurut Tiara (2012) dalam(Nurhasanah, 2013)), edema cukup berbahaya bagi ibu hamil karena bisa menyebabkan gangguan pada jantung, ginjal dan lain sebagainya sehingga menyebabkan organ tubuh tersebut tidak berfungsi sebagaimana mestinya. Selain perubahan fisik, ibu hamil trimester III juga akan mengalami perubahan psikologis seperti ketakutan, kekhawatiran, dan kecemasan (Padila, 2015). Kecemasan merupakan keadaan emosi tanpa objek tertentu, bingung, khawatir pada sesuatu yang terjadi dengan penyebab yang tidak pasti dan perasaan tidak menentu dan tidak berdaya. Hal ini dipicu oleh hal yang tidak dapat diketahui dan menyertai semua hal dan pengalaman baru, seperti masuk sekolah, memulai rumah tangga baru, memulai pekerjaan baru, atau melahirkan anak. Karakteristik ansietas ini yang membedakan dari rasa takut (Stuart, 2015;Mayasari, 2011). Perasaan cemas selama kehamilan dapat menimbulkan dampak fisik maupun psikis ibu hamil dan janin.

Untuk mengurangi dampak adanya edema kaki dan kecemasan pada ibu hamil trimester III tersebut dapat diakukan beberapa cara seperti berpikir positif, berdo'a, berbagi cerita, meditasi dan hidroterapi (Widyastuti, 2014). Hidroterapi merupakan pengobatan ilmiah dengan menggunakan air untuk menyembuhkan dan mengurangi nyeri serta berbagai penyakit ringan melalui cara yang berbeda. Hidroterapi digunakan untuk berbagai penyakit, seperti pemulihan vitalitas tubuh, meredakan nyeri pada osteoarthritis (nyeri sendi) (Amal, 2010). Salah satu bentuk hidroterapi yaitu rendam kaki menggunakan air hangat. Rendam kaki air hangat merupakan kondisi kaki yang kontak langsung 
dengan air hangat. Rendam kaki air hangat dilakukan pada suhu $38^{0}-39^{\circ} \mathrm{C}$. Rendam air hangat sangat mudah dilakukan oleh semua orang, tidak membutuhkan biaya yang mahal, dan tidak memiliki efek samping yang berbahaya.

Selain itu, terapi rendam air hangat juga dapat digunakan untuk menghindari komplikasi dari terapi farmakologis (diuretikum) yang jika digunakan secara tidak hati-hati dapat menyebabkan kehilangan volume cairan hingga memperburuk perfusi utero-plasenta, meningkatkan hemokonsentrasi, menimbulkan dehidrasi janin, dan menurunkan berat janin. Akmal (2010) menjelaskan tentang prinsip dasar merendam kaki dengan air hangat dapat mengakibatkan vasodilatasi pembuluh darah yang mengakibatkan aliran darah menjadi lancar sehingga otot dapat berelaksasi. Banyak kegunaan rendam kaki dengan air hangat bagi kesehatan. Penelitian oleh Santoso (2015) bahwa rendam kaki dengan air hangat mampu menurunkan tekanan darah.

Selain itu, pelaksanaan rendam kaki dengan air hangat juga dapat menurunkan tingkat kecemasan pada tingkat kecemasan ringan dan sedang yang dialami ibu hamil pada trimester III hal ini dibuktikan dengan penelitian yang dilakukan oleh Darmasanti, dkk (2018) didapatkan bahwa terapi rendam kaki yang dilakukan berulang dan teratur sebanyak tiga kali dalam kurun waktu 2 hari pada setiap tindakan dapat menurunkan tingkat kecemasan pada ibu hamil trimester III. Lestari, dkk (2018) juga menyatakan bahwa terapi rendam kaki dengan air hangat dapat mengurangi edema kaki fisiologis pada ibu hamil trimester III yang belum mendapatkan pengobatan apapun.

\section{METODE}

Pengabdian masyarakat ini dilaksanakan di Aula Puskesmas Air dingin Padang. Kegiatan ini dilaksanakan pada tanggal 10 Oktober 2019. Pengabdian masyarakat ini dilakukan dengan penyuluhan melalui metode ceramah, diskusi dan demonstrasi. Metode ceramah dilakukan untuk menjelaskan teori dari udema dan kecemasab pada kehamlan trimerter III mulai dari pengertian, penyebab, tanda gejala, jenis, akibat lanjut serta penanganan. Metode diskusi dilakukan dengan memberikan kesempatan kepada pasien/keluarga untuk mengeluarkan pendapat/ pertanyaan tentang materi yang masih kurang paham dan metode demonstrasi dilakukan praktek rendam kaki dan mengajarkan ibu agar mampu melakukan teknik rendam kaki sesuai dengan langkah-langkah yang benar. Kegiatan ini diikuti oleh 22 orang ibu hamil trimester III.

\section{HASIL DAN PEMBAHASAN}

Pada tanggal 10 Oktober 2019 acara direncanakan pada jam 09.00 Wib, terlaksana sesuai dengan waktu yang ditetapkan yaitu jam 09.00 wib, ketepatan ini didukung oleh hamil sudah dikontrak I hari 
sebelum kegiatan penyuluhan, pasien beserta keluarga antusias atas penyuluhan yang diberikan. Kegiatan penyuluhan ini juga didukung oleh perawat Puskesmas dan mahasiswa yang sedang praktek profesi di Puskemas Air Dingin. Pelaksanaan kegiatan penyuluhan ini selesai 10.00 wib sesuai dengan kontrak waktu semula.

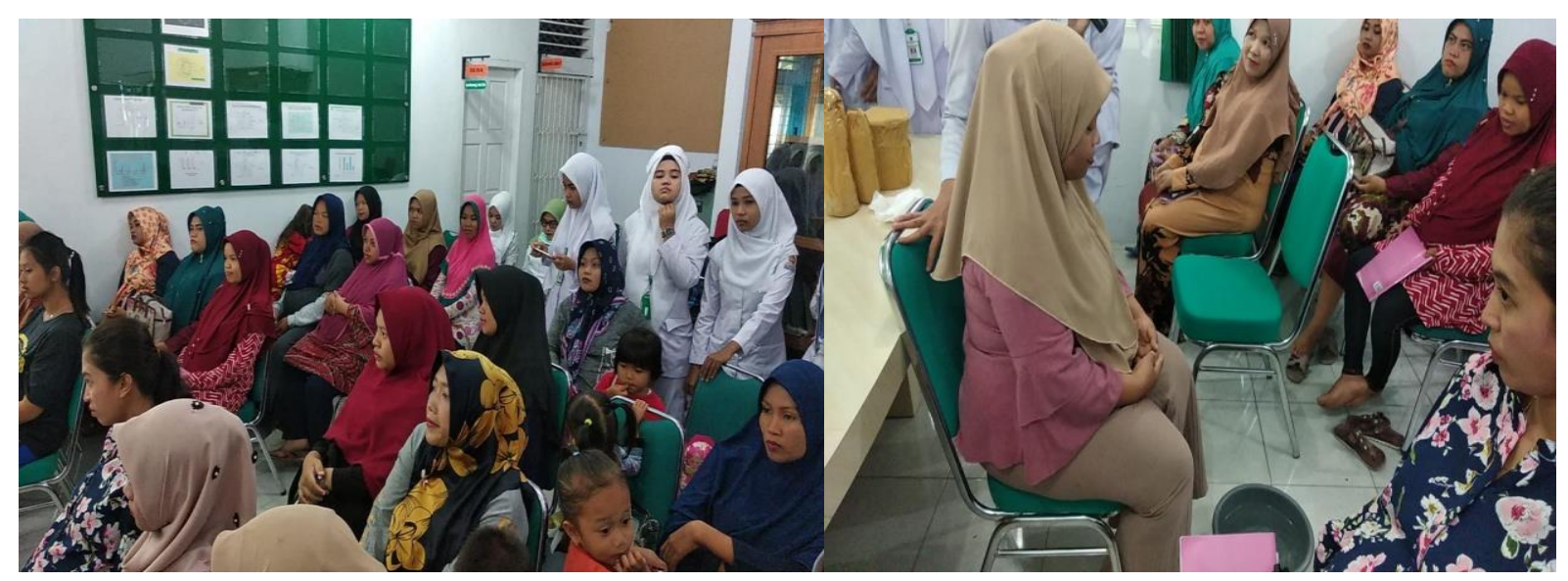

Gambar 1. Penyuluhan Kesehatan pada Ibu hamil trimester III

Para peserta/audiens kegiatan pengabdian masyarakat dapat mengikuti seluruh kegiatan pengabdian masyarakat penyuluhan dan semua peserta berperan aktif dalam kegiatan pengabdian masyarakat karena terlihat peserta aktif bertanya tentang pengabdian masyarakat penyuluhan tentang Manajemen nyeri persallinan. Selama pelaksanaan kegiatan suasana tenang dan peserta/ audiens memperhatikan penyuluhan dengan penuh perhatian dan fokus, saat mendemonstrasikan rendam kaki.

Waktu berlangsung kegiatan dari awal sampai akhir selama 60 menit yaitu meliputi perkenalan antara tim kegiatan pengabdian masyarakat dengan peserta/audiens yang hadir dengan menjelaskan kontrak waktu dan bahasa, penyampaian materi udem kaki dan kecemasam kepada ibu hamil trimester tiga, sesi tanya jawab mengenai topik yang belum dimengerti oleh audiensi tentang udem kaki dan kecemasam kepada ibu hamil trimester tiga dan cara rendam kaki, serta melakukan evaluasi kembali yang termasuk dalam tahap penutup dan kegiatan ini selesai pukul 10.00 wib.

Evaluasi struktur didapatkan waktu sesuai dengan perencanaan yaitu 60 menit, setting tempat dan alat sudah sesuai dengan yang direncanakan, pengorganisasian sesuai dengan perencanaan, audiens duduk di kursi didampingi oleh fasilitator sesuai dengan perencanaan. Evaluasi proses didapatkan pelaksanaan kegiatan melebihi dari yang direncanakan 30 menit karena audiens banyak yang bertanya dan mendemonstrasikan langsung teknik rendam kaki, audiens berperan aktif dan dapat mengikuti 
kegiatan pengabdian masyarakat sebanyak 22 orang, audiens berperan serta aktif dalam kegiatan dengan aktif bertanya tentang hal yang tidak diketahui dan dipahaminya, audiens dapat mengikuti acara atau kegiatan penyuluhan sampai selesai, tim kegiatan pengabdian masyarakat hadir tepat waktu dan berperan sesuai dengan perannya. Evaluasi hasil didapatkan $80 \%$ Audiens yang hadir mampu menyebutkan pengertian udem kaki dan kecemasan, 90\% Audiens yang hadir mampu menyebutkan komplikasi udem kaki dan kecemasan, 90\% Audiens yang hadir mampu menyebutkan penanganan udem kaki dan kecemasan, 75\% Audiens yang hadir mampu menyebutkan dan mendemonstrasikan cara rendam kaki air hangat. Pendidikan kesehatan ini dapat meningkatkan pengetahuan dan perilakukan dari ibu hamil trimester III.

Tujuan pendidikan kesehatan adalah untuk membentuk perubahan sikap dan tingkah laku individu, keluarga, kelompok khusus, dan masyarakat dalam membina serta memelihara perilaku hidup sehat dan juga agar dapat berperan aktif dalam mewujudkan derajat kesehatan yang optimal (Nursalam, 2009). Menurut Notoadmodjo (2012) peranan pendidikan kesehatan adalah melakukan intervensi terhadap faktor perilaku sehingga perilaku individu, maupun kelompok sesuai dengan nilai-nilai kesehatan. Pengetahuan tentang kesehatan akan berpengaruh terhadap perilaku sebagai hasil jangka menengah (intermediate impact) dari pemberian pendidikan kesehatan tersebut. Setelah itu perilaku kesehatan akan berpengaruh pada peningkatan indikator kesehatan individu atau kelompok sebagai keluaran (outcome) pendidikan kesehatan.

\section{SIMPULAN}

Ada peningkatan pengetahuan pada ibu hamil trimester III terkait penanganan udem dan kecemasan yang meliputi pengetahuan dan demonstrasi rendam kaki air hangat. Hal ini terbukti dengan diskusi banyak sekali keinginan tahuan mereka tentang cara pencegahan dan penanggulangan masalah kesehatan terutama keluhan ibu selama trimester III. Kegiatan pengabdian ini mampu meningkatkan pengetahuan dan pemahaman ibu hamil trimester III. Metode ceramah dan demosntrasi dapat digunakan oleh tenaga kesehatan sebagai salah satu cara pendidikan kesehatan kepada masyarakat khususnya ibu hamil trimester III. 
JAMALI - Volume. 02, Issue. 02, September 2020

\section{UCAPAN TERIMA KASIH}

Penulisan ini dapat terwujud dan terselesaikan dengan baik karena adanya bantuan dari berbagai macam pihak, terima kasih kepada: 1.Ketua Yayasan Mercubaktijaya beserta staf dan jajaranya. 2.Ketua Stikes Mercubaktijaya Padang beserta seluruh civitas akademika. 3.Pihak terkait yang telah membantu dalam kelancaran pelaksanaan penelitian. Dalam penyusunan ini, penulis menyadari masih banyak kekurangan karena keterbatasan pengetahuan. Oleh karena itu, segala kritik dan saran yang bersifat membangun sangat penulis harapkan. Semoga penelitian ini dapat memberikan manfaat dan dapat menjadi salah satu bahan informasi pengetahuan bagi para pembaca sekalian.

\section{DAFTAR PUSTAKA}

Akmal, M., dkk.(2010).Ensiklopedia Kesehatan.Yogyakarta:Ar-Razz Media

Guyton, A.C., \& Hall, J.E. (2007). Fisiologi Kedokteran. Jakarta: EGC

Handayani, R. (2015). Faktor-Faktor Yang Berhubungan Dengan Tingkat Kecemasan Menjelang Persalinan Pada Ibu Primigravida Trimester III Di Wilayah Kerja Puskesmas Lubuk Buaya Padang Tahun 2012. Ners Jurnal Keperawatan. 1907-686X, II(1)

Hidayat, S., \& Sumarni, S. (2014). Kecemasan Ibu Hamil Dalam Menghadapi Proses Persalinan. Jurnal Kesehatan Hidayati, D.S. (2014). Latar Belakang Psikologis Kecemasan Ibu Hamil Usia 35 Tahun Keatas. Jurnal Ilmiah Psikologi Terapan., 2.(2).2301-8267

Notoadmojo, S. (2010). Promosi Kesehatan : Teori Pengetahuan dan Prilaku, Edisi Revisi . Jakarta : Rineka Cipta

Potter\&Perry. (2010). Fundamental Keperawatan Ed 7 Buku 2. Jakarta: Salemba Medika

Widyastuti, P. (2014). Manajemen Stress. Jakarta: EGC 